\title{
Rapid Oxidation of Paracetamol by Cobalt(II) Catalyzed Sulfite at
}

\author{
Alkaline pH \\ Yanan Yuan ${ }^{1,2}$, Dan Zhao ${ }^{1}$, Jinjun $\mathrm{Li}^{1}$, Feng Wu ${ }^{1 *}$, Marcello Brigante ${ }^{2}$, Gilles \\ Mailhot $^{2^{*}}$ \\ ${ }^{1}$ Department of Environmental Science, School of Resources and Environmental Science, \\ Wuhan University, Wuhan, 430079, China. \\ ${ }^{2}$ Université Clermont Auvergne, CNRS, SIGMA Clermont, Institut de Chimie de \\ Clermont-Ferrand, F-63000 Clermont-Ferrand, France. \\ Corresponding Authors: Feng Wu (fengwu@whu.edu.cn) and Gilles Mailhot \\ (gilles.mailhot@uca.fr)
}

\section{Abstract}

In this study we have investigated the efficiency Cobalt (II) (Co(II)) for the activation of sulfite ions following the oxidation of paracetamol used as model contaminants. Physico-chemical parameters that can impact the paracetamol degradation $(\mathrm{pH}$, initial paracetamol concentration, $\mathrm{Co}(\mathrm{II}) / \mathrm{S}(\mathrm{IV})$ molar ratio, oxygen concentration) and contribution of various radicals were investigated in order to elucidate the chemical mechanism. Main results show that the $\mathrm{pH}$ is a key factor controlling the efficiency in the system $\mathrm{Co}(\mathrm{II}) /$ Sulfite. Higher efficiency is observed for $\mathrm{pH}$ between 9.0 and 10.0. Increasing S(IV) concentrations, until $1 \mathrm{mM}$, slightly promoted the degradation of paracetamol. In fact, an excess of sulfite ions inhibits the reaction through the scavenging of $\mathrm{SO}_{4}{ }^{--}$and $\mathrm{SO}_{5}{ }^{\bullet-}$. Moreover, degradation efficiency drastically decreases from $\sim 85 \%$ to less than $5 \%$ in absence of oxygen. $\mathrm{SO}_{4}{ }^{--}$was confirmed to be the main oxidant responsible for the paracetamol degradation. For the first time we determined the second order rate constant between $\mathrm{SO}_{4}{ }^{--}$and paracetamol $\left(1.33 \pm 0.79 \times 10^{9} \mathrm{M}^{-1}\right.$ $\mathrm{s}^{-1}$ (at $\left.\mathrm{pH} 5\right)$ and $6.14 \pm 0.99 \times 10^{8} \mathrm{M}^{-1} \mathrm{~s}^{-1}$ (at $\left.\mathrm{pH} 11.0\right)$ ). Moreover, radical-scavenging experiments also suggest the possible implication of $\mathrm{SO}_{5}{ }^{\bullet-}$. Hence, this work provides a precise understanding of the overall mechanism and a new 
promising strategy by using sulfite and transition metal such as $\mathrm{Co}(\mathrm{II})$ to promote organic compounds degradation in water under neutral and alkaline $\mathrm{pH}$ conditions.

\section{Keywords}

Sulfate radical, sulfite ion, cobalt ion, advanced oxidation processes, paracetamol.

\section{Introduction}

Advanced oxidation processes based on sulfate radical (SR-AOPs) have emerged as a promising method in the field of oxidative decontamination of polluted water and soil [1-3]. Sulfate radical $\left(\mathrm{SO}_{4}{ }^{-}\right)$, a strong one-electron oxidant, has relatively high standard redox potential $\left(\mathrm{E}^{0}=2.6 \mathrm{~V} v s \mathrm{NHE}\right)$ with an oxidation potential comparable to or even higher than that of hydroxyl radical [4]. Moreover, $\mathrm{SO}_{4}{ }^{--}$can react via electron transfer, by addition to $\mathrm{C}-\mathrm{C}$ double bonds and $\mathrm{H}$-abstraction $[5,6]$, thus, it is able to oxidize a large number of pollutants such as phenol derivatives and aniline in water [7-9]. $\mathrm{SO}_{4}{ }^{--}$can be generated in homogeneous or heterogeneous systems via photolysis, thermolysis and radiolysis $[10,11]$ or via transition metal activation of persulfate $\left(\mathrm{S}_{2} \mathrm{O}_{8}{ }^{2-}, \mathrm{PS}\right)[7,12-15]$ and peroxymonosulfate $\left(\mathrm{SO}_{5}{ }^{2-}, \mathrm{PMS}\right)[16,17]$.

In fact, PMS can be activated by various transition metals such as $\mathrm{Fe}, \mathrm{Mn}, \mathrm{Ni}$ and $\mathrm{Co}$ in the homogenous systems $[1,18]$. Among them, Co and Fe are the most commonly used metal to promote radical formation due to their occurrence in natural media and low cost. Huang and Huang investigated the ability of Co(II) and PMS system to degrade Bisphenol $\mathrm{A}$ at $\mathrm{pH}$ 7, and achieved an efficient detoxification and mineralization method [19]. A process based on the sulfate radicals generation through iron (Fe(II), Fe(III)) activation of PMS or PS was studied for polychlorinated biphenyls degradation in aqueous system [20]. The high oxidation efficiency and slow rate of consumption of the oxidants make metal-mediated activation system a feasible strategy for degradation of recalcitrant organic compounds. Furthermore, PMS activation using cobalt oxide or cobalt-metal oxide as heterogeneous catalysts also gains significant relevance in water treatment applications [21]. The cobalt oxides such as $\mathrm{CoO}, \mathrm{CoO}_{2}$, $\mathrm{CoO}(\mathrm{OH}), \mathrm{Co}_{2} \mathrm{O}_{3}$ and $\mathrm{Co}_{3} \mathrm{O}_{4}, \mathrm{Fe}-\mathrm{Co}$ mixed oxide nanocatalysts, cobalt oxide 
supported on $\mathrm{MgO}(\mathrm{Co} / \mathrm{MgO})$, on $\mathrm{TiO}_{2}\left(\mathrm{Co} / \mathrm{TiO}_{2}\right)$ and $\mathrm{Co}_{3} \mathrm{O}_{4} / \mathrm{TiO}_{2}$ and combined with other metals were used as efficient heterogeneous catalysts for activation of PMS [22-25]. The most advantage of heterogeneous catalyst is that solid particles can be easily removed from liquid phase and, in some cases, reused.

Recently, sulfite ions were found to react with transition metals such as $\mathrm{Fe}(\mathrm{II})$, $\mathrm{Fe}(\mathrm{III})$ and $\mathrm{Cr}(\mathrm{VI})$ to generate $\mathrm{SO}_{4}{ }^{--}$and application for the azo dyes and amine compounds decontamination was tested [17, 26-30].

In our previous work, we reported some novel AOPs using Fe(II)-sulfite, $\mathrm{Fe}(\mathrm{III})$-sulfite, photo-Fe(II)-sulfite system able to produce oxysulfur radicals (including $\mathrm{SO}_{3}{ }^{--}, \mathrm{SO}_{4}{ }^{--}$and $\mathrm{SO}_{5}{ }^{\circ}$ ). Combined with the work conducted by other researchers [31-33], the basic chain oxidation mechanisms of oxysulfur radicals generation has been investigated.

In this work, $\mathrm{Co}(\mathrm{II})$-sulfite ions (S(IV)) system has been investigated to promote the paracetamol degradation in water. Paracetamol (PARA) is a widely used analgesic and antipyretic drug and an important material for the manufacturing of azo dyes. PARA was chosen as a target contaminant in this work due to its presence in the environment from several emissions from manufacturing facilities, consumer use and disposal, and hospital waste $[34,35]$. The effect of $\mathrm{pH}$, initial PARA concentration, $\mathrm{Co}(\mathrm{II}) / \mathrm{S}(\mathrm{IV})$ molar ratio, the presence of oxygen were investigated. Moreover, the activation mechanism and contribution of reactive oxygen and sulfur species were elucidated by using different kinds of radical scavengers and transient absorption spectroscopy.

\section{Materials and Methods}

\subsection{Chemicals}

Cobalt(II) sulfate $\left(\mathrm{CoSO}_{4} \cdot 7 \mathrm{H}_{2} \mathrm{O}\right.$, analytical reagent grade), Cobalt(II) oxide (CoO) and Paracetamol $\left(\mathrm{C}_{8} \mathrm{H}_{9} \mathrm{NO}_{2}\right)$, were purchased from Sinopharm Chemical Reagent Co., Ltd. Sulfite solutions (from $\mathrm{Na}_{2} \mathrm{SO}_{3}$, Sinopharm Chemical Reagent Co., Ltd) were prepared just prior to measurements. The radical scavengers tert-butyl alcohol (TBA), 
ethanol (EtOH) as well as $\mathrm{NaOH}$ and $\mathrm{H}_{2} \mathrm{SO}_{4}$ which were used to adjust the $\mathrm{pH}$ of the solutions, were obtained from Sinopharm Chemical Reagent Co., Ltd. Methanol was HPLC grade and purchased from Fisher Corporation. Ammonium thiocyanate $\left(\mathrm{NH}_{4} \mathrm{SCN}\right)$ and Methyl isobutyl ketone (MIK) used to determine the concentration of Co(II), were obtained from Sigma, France. All chemicals were used without further purification. Ultrapure water with $18.2 \mathrm{M} \Omega \mathrm{cm}$ resistivity used in this work was obtained through a water purification system.

\subsection{Degradation experiments}

All experiments were conducted in a $250 \mathrm{~mL}$ open cylindrical reactor cooled by an external jacket water circulation at a constant temperature of $25^{\circ} \mathrm{C}$. Appropriate amounts of the PARA, scavengers and $\mathrm{Na}_{2} \mathrm{SO}_{3}$ were mixed in the solution and the $\mathrm{pH}$ was adjusted using a pHS-3C pH meter by adding dilute $\mathrm{NaOH}$ and $\mathrm{H}_{2} \mathrm{SO}_{4}$ until desired value. Each solution was constantly stirred with a Polytetrafluoroethylene (PTFE)-coated magnetic stirrer and purged with air with a fixed flow of $0.8 \mathrm{~L} \mathrm{~min}^{-1}$.

Each experiment was initialed spiking with $\mathrm{Co}(\mathrm{II})$ or $\mathrm{CoO}$ into the solution. Samples were withdrawn at fixed interval times and analyzed immediately to determine the remaining concentration of PARA and $\mathrm{Co}(\mathrm{II})$. For radical-scavenging experiments, specific concentrations of TBA or EtOH were added to the solutions before $\mathrm{Co}$ (II) addition. In order to assess the role of oxygen during $\mathrm{Co}$ (II)-sulfite solution were purged by bubbling $\mathrm{N}_{2}$ (99.99\%) or $\mathrm{O}_{2}(99.99 \%)$ for $30 \mathrm{~min}$ before and throughout the experiment. A dissolved oxygen (DO) meter (8403, AZ Instrument Co. Ltd.) was used to determine the oxygen concentration in solution. During anoxic reaction, the DO was $0.01 \mathrm{mg} \mathrm{L}^{-1}$ while for $\mathrm{O}_{2}$ saturated solution a concentration of $20 \mathrm{mg} \mathrm{L}^{-1}$ was determined. All experiments were carried at least two times.

\subsection{Chemical analysis}

The concentration of PARA was determined using a high-performance liquid chromatography (HPLC) Shimadzu LC-10A system equipped with UV-vis detector (SPD-10AV; Shimadzu) and an ODS-C18 column $(25 \mathrm{~cm} \times 4.6 \mathrm{~mm}, 5 \mu \mathrm{m}$; Shimadzu, Kyoto, Japan). The separation was warried out using methanol:water (25:75 v/v) as 
122 isocratic mobile phase at a flow rate of $1.0 \mathrm{~mL} \mathrm{~min}^{-1}$. The detector was set at $241 \mathrm{~nm}$.

123 The concentration of Co(II) in solution was determined by Methyl isobutyl ketone and 124 Ammonium thiocyanate (see Supplementary material for the method description and 125 Fig. S1) [36]. An optical-fiber coupled to a spectrophotometer (UV-1601 Shimadzu, 126 Japan) was used to scan the UV-vis absorption spectra of $\mathrm{Co}(\mathrm{II})-\mathrm{SO}_{3}{ }^{2-}$ complex.

127 For $\mathrm{SO}_{4}{ }^{--}$reactivity a laser flash photolysis (LFP) system was used with $266 \mathrm{~nm}$ 128 excitation following the procedure reported by $\mathrm{Wu}$ at al. [15]. Analysis of transient 129 decay and second order rate constant determination (using PARA concentrations from 1300 to $0.1 \mathrm{mM}$ ) were determined at $470 \mathrm{~nm}$ corresponding to the maximum absorption 131 of $\mathrm{SO}_{4}{ }^{--}$. The second order rate constants were determined at $\mathrm{pH} 5.0$ and 11.0 132 corresponding to the molecular and deprotonated forms respectively of PARA ( $\mathrm{pKa}=$ $1339.5)$.

\section{Results and discussion}

\subsection{Effect of initial pH on paracetamol degradation}

The effect of the initial $\mathrm{pH}$ on the $\mathrm{Co}(\mathrm{II})+\mathrm{S}(\mathrm{IV})$ system oxidation of PARA was investigated from 3.0 to 11.0. The initial concentrations of $\mathrm{Co}(\mathrm{II})$ and $\mathrm{SO}_{3}{ }^{2-}$ were 0.1 $\mathrm{mM}$ and $1.0 \mathrm{mM}$, respectively and during the reaction, air (otherwise stated) was constantly bubbled at a flow rate of $0.8 \mathrm{~L} \mathrm{~min}^{-1}$. The PARA degradation shows a strong pH-dependence as illustrated in Fig. 1A. Despite a negligible degradation at relatively acidic values $(\mathrm{pH} 3.0$ - 5.0), PARA degradation is enhanced from $\mathrm{pH} 5.0$ to $\mathrm{pH} 10.0$ while a decrease is observed at $\mathrm{pH}$ 11.0. It is interesting to observe that degradation efficiency between $\mathrm{pH} 3.0$ and 10 is strongly correlated to the $\mathrm{HSO}_{3}{ }^{-} / \mathrm{SO}_{3}{ }^{2-}$ speciation in solution ( $\mathrm{pKa}=7.2)$ as shown in Fig. 1B in which degradation of PARA after $30 \mathrm{~min}$ at different $\mathrm{pH}$ values is correlated to the concentration of $\mathrm{SO}_{3}{ }^{2-}$ in solution. However, at $\mathrm{pH} 11$, the inhibition of PARA degradation can be attributed to the formation of insoluble Cobalt-hydroxide $\left(\mathrm{Co}(\mathrm{OH})_{2}\right)$ complex that is expected to precipitate in solution [37]. 
152 is more reactive toward $\mathrm{SO}_{3}{ }^{2-}$ compared to $\mathrm{HSO}_{3}{ }^{-}$would be formed at alkaline $\mathrm{pH}$ 153 values (R1) leading to the formation of a $\mathrm{Co}(\mathrm{II})-\mathrm{SO}_{3}$ complex [27]. $\mathrm{Co}(\mathrm{II})-\mathrm{SO}_{3}$ could 154 be oxidized to $\mathrm{Co}(\mathrm{III})-\mathrm{SO}_{3}{ }^{+}$complex in the presence of dissolved oxygen as reported in 155 different works ( $\mathrm{R} 2$ and $\mathrm{R} 3$ ) [38]. $\mathrm{SO}_{3}{ }^{--}$could be generated during the redox reaction 156 between the $\mathrm{Co}(\mathrm{III})-\mathrm{SO}_{3}{ }^{+}$complex and $\mathrm{SO}_{3}{ }^{2-}$ (R4).

UV-vis absorption spectra of Co(II), S(IV), Co(II) and S(IV) during the reaction (Fig. S1) were acquired to investigate the complexation between Co(II) and S(IV). The result showed that: only $\mathrm{Co}(\mathrm{II})$ or $\mathrm{S}(\mathrm{IV})$ at $\mathrm{pH} 9.0$ did not show absorption in the range 250-600 $\mathrm{nm}$. However, when S(IV) was added to the solution containing 0.1 mM Co(II) an absorption band absorbing up to $\sim 600 \mathrm{~nm}$ is present. The presence of this new absorption band demonstrates that the Co(II)-S(IV) complex could be formed and decreasing in the absorption during time proved the reaction between $\mathrm{Co}(\mathrm{II})$ and $\mathrm{S}(\mathrm{IV})$, and corresponding depletion of S(IV).

$\mathrm{Co}(\mathrm{III})-\mathrm{SO}_{3}^{+}+\mathrm{SO}_{3}^{2-} \rightarrow \mathrm{Co}(\mathrm{II})-\mathrm{SO}_{3}+\mathrm{SO}_{3}^{\bullet-}$

The $\mathrm{pH}$ represents also a key factor influencing the $\mathrm{SO}_{3}{ }^{--}$reactivity in water. In fact, the primary step is the oxygen-mediated oxidation of $\mathrm{SO}_{3}{ }^{--}$to $\mathrm{SO}_{5}{ }^{--}$(R5), this latter can react with $\mathrm{HSO}_{3}{ }^{-} / \mathrm{SO}_{3}{ }^{2-}$ leading to the formation of $\mathrm{SO}_{3}{ }^{\bullet-}$ and $\mathrm{SO}_{4}{ }^{\bullet-}$ (R6-R9). As reported in $\mathrm{R} 6$ and $\mathrm{R} 8, \mathrm{SO}_{5}{ }^{--}$could react with $\mathrm{SO}_{3}{ }^{2-}$ to generate $\mathrm{SO}_{3}{ }^{--}$and $\mathrm{SO}_{4}{ }^{--}$at a rate constant around $10^{5}-10^{6} . \mathrm{SO}_{4}{ }^{--}$could react with PARA or with $\mathrm{SO}_{3}{ }^{2-}$ leading to the generation $\mathrm{SO}_{3}{ }^{--}(\mathrm{R} 10)$, then a $\mathrm{SO}_{\mathrm{x}}{ }^{--}\left(\mathrm{SO}_{3}{ }^{--}, \mathrm{SO}_{4}{ }^{--}\right.$and $\left.\mathrm{SO}_{5}{ }^{\circ-}\right)$ cycle can be achieved. However, in the presence of $\mathrm{HSO}_{3}{ }^{-}$(acidic conditions), $\mathrm{SO}_{5}{ }^{--}$reacts with $\mathrm{HSO}_{3}{ }^{-}$to generate $\mathrm{SO}_{4}{ }^{-} / \mathrm{SO}_{3}{ }^{--}$with a relatively shower rate constants (R7 and R9) 
180

compared to the reactivity with $\mathrm{SO}_{3}{ }^{2-}$. The overall reaction rate between $\mathrm{SO}_{5}{ }^{--}$and $\mathrm{SO}_{3}{ }^{2-}$ is $\sim 1-2$ orders of magnitude higher than between $\mathrm{SO}_{5}{ }^{--}$and $\mathrm{HSO}_{3}{ }^{-}$.

$$
S O_{3}^{\cdot-}+O_{2} \rightarrow S O_{5}^{--} \quad \mathrm{k}=(1.5-2.5) \times 10^{9} \mathrm{M}^{-1} \mathrm{~s}^{-1} \quad[39,40]
$$

$\mathrm{SO}_{5}^{\bullet-}+\mathrm{SO}_{3}^{2-} \rightarrow \mathrm{SO}_{4}^{2-}+\mathrm{SO}_{4}^{\bullet-} \mathrm{k}=9 \times 10^{6} \mathrm{M}^{-1} \mathrm{~s}^{-1}$

$\mathrm{SO}_{5}^{\bullet-}+\mathrm{HSO}_{3}^{-} \rightarrow \mathrm{HSO}_{4}^{-}+\mathrm{SO}_{4}^{\bullet-} \mathrm{k}=2.5 \times 10^{4} \mathrm{M}^{-1} \mathrm{~s}^{-1} \quad$ [42]

$\mathrm{SO}_{5}^{\bullet-}+\mathrm{SO}_{3}^{2-} \rightarrow \mathrm{SO}_{5}^{2-}+\mathrm{SO}_{3}^{--} \mathrm{k}=3.8 \times 10^{6} \mathrm{M}^{-1} \mathrm{~s}^{-1}$

$\mathrm{SO}_{5}^{\bullet-}+\mathrm{HSO}_{3}^{-} \rightarrow \mathrm{HSO}_{5}^{-}+\mathrm{SO}_{3}^{\bullet-} \mathrm{k}=7.5 \times 10^{4} \mathrm{M}^{-1} \mathrm{~s}^{-1}$

$\mathrm{SO}_{4}^{\bullet-}+\mathrm{SO}_{3}^{2-} \rightarrow \mathrm{SO}_{4}^{2-}+\mathrm{SO}_{3}^{\bullet-} \mathrm{k}=5.7 \times 10^{8} \mathrm{M}^{-1} \mathrm{~s}^{-1}$

$\mathrm{SO}_{4}^{\bullet-}+\mathrm{HSO}_{3}^{-} \rightarrow \mathrm{HSO}_{4}^{-}+\mathrm{SO}_{3}^{\bullet-} \mathrm{k}=7.5 \times 10^{8} \mathrm{M}^{-1} \mathrm{~s}^{-1}$

\subsection{S(IV) and Co(II) effect on the PARA degradation}

Different amounts of Co(II) were used to investigate the effect of $\mathrm{Co}(\mathrm{II})$ concentration on the PARA removal at $\mathrm{pH} 9.0$ (Fig. 2A). When experiments were conducted using a $\mathrm{Co}(\mathrm{II})$ concentration between 0.05 and $0.15 \mathrm{mM}$ and a fixed sulfite concentration of $1.0 \mathrm{mM}$, no significant differences were observed on the PARA degradation profile. One of reasons explaining the slightly effect of $\mathrm{Co}$ (II) concentration may be the fast recycle of $\mathrm{Co}(\mathrm{II})$ and $\mathrm{Co}(\mathrm{III})$ in the presence of a stoichiometry excess of S(IV) concentrations in aerated solution (R3-R4). Moreover, when the concentration of $\mathrm{Co}$ (II) was monitored during the reaction (see the Supplementary material for the method description), it was found that its concentration was nearly stable (Fig. S3). Such results suggest that in the presence of enough sulfite in solution, the cobalt recycle could achieved very fast leading to the generation of $\mathrm{SO}_{3}{ }^{--}$at the same time. Even the addition of $\mathrm{Co}(\mathrm{II})$ didn't play a relevant role on the paracetamol degradation, but for the sake of feasibility and accuracy, $0.1 \mathrm{mM} \mathrm{Co}$ (II) was employed during all experiments, as when the experiments were conducted under low concentration of $\mathrm{Co}$ (II) such as $0.05 \mathrm{mM}$, the repeatability could not be ensured 
every time.

The dependence of the PARA degradation on the initial concentration of S(IV) was also investigated (Fig. 2B). An increase in S(IV) concentration (between 0.5 to 1 $\mathrm{mM}$ ) accelerate the PARA degradation being, through $\mathrm{Co}(\mathrm{II})$ reactivity, a source of $\mathrm{SO}_{3}{ }^{\bullet-}$. However, at higher sulfite ions concentrations $(2 \mathrm{mM})$ there is no more enhancement of PARA degradation and this effect could be attributed to the reactivity competition of $\mathrm{SO}_{4}{ }^{--} / \mathrm{SO}_{5}{ }^{--}$between PARA and $\mathrm{SO}_{3}{ }^{2-}$ (R8 and R10). Hence, the balance between S(IV) concentration and its catalytic character is a key factor for the oxidative system efficiency.

In all these experiments (Fig. 2) it is impossible to obtain more than $90 \%$ of PARA degradation. This observation is certainly due to a competition reaction of the sulfate radicals on PARA, the excess of sulfite and the degradation products of PARA. After a short period of time sulfate radicals react no more on paracetamol due to its low concentration.

\subsection{Effect of $\mathrm{O}_{2}$}

The effect of oxygen concentration on the PARA degradation using $0.1 \mathrm{mM}$ of $\mathrm{Co}(\mathrm{II})$ and $1 \mathrm{mM}$ of $\mathrm{S}(\mathrm{IV})$ was investigated comparing results from aerated and nitrogen-purged solutions. When experiment was conducted in aerated solution (under air bubbling), a PARA degradation plateau was reached after first 10 min corresponding to $\sim 82 \%$ of degradation (Fig. 3). However, under nitrogen-saturated solution, the efficiency dropped to less than $8 \%$ confirming that oxygen is a crucial parameter. Oxygen strongly favors the degradation of pollutant through $\mathrm{SO}_{3}{ }^{--}$oxidation into $\mathrm{SO}_{5}{ }^{\bullet-}$ that undergo further reaction to form $\mathrm{SO}_{4}{ }^{--}$in the solution (R5-R7).

\subsection{Radical species involvement}

The second order rate constants of sulfate radical with molecular and deprotonated PARA (at pH 9.0, pH used in our experiments, about $25 \%$ of PARA is under deprotonated form) were determined from the linear fit of pseudo-first order decay monitored at $470 \mathrm{~nm}$ (corresponding to the maximum absorption of sulfate radical) $v s$ 
concentration of PARA in solution (Fig. S4). The second order rate constant was estimated to be $1.33 \pm 0.79 \times 10^{9} \mathrm{M}^{-1} \mathrm{~s}^{-1}$ (at pH 5) and $6.14 \pm 0.99 \times 10^{8} \mathrm{M}^{-1} \mathrm{~s}^{-1}$ (at pH 11.0) corresponding respectively to the molecular and deprotonated form, on the phenol group, of PARA.

To shed light onto radical mechanism involved in such system, EtOH and TBA were used as radical scavengers. This competition kinetic approach is based on the different second-order rate constant with $\mathrm{HO}^{\bullet}$ and $\mathrm{SO}_{4}{ }^{--}\left(k_{T B A, H O}{ }^{\circ}=6.0 \times 10^{8} \mathrm{M}^{-1} \mathrm{~s}^{-1}\right.$ [44] which is nearly three orders of magnitude higher than $k_{T B A, S O_{4}^{--}}=8.5 \times 10^{5} \mathrm{M}^{-1} \mathrm{~s}^{-1}$ [45] and $k_{E t O H, H O^{\circ}}=1.9 \times 10^{9} \mathrm{M}^{-1} \mathrm{~s}^{-1}[44], k_{E t O H, S O_{4}^{-}}=5.6 \times 10^{7} \mathrm{M}^{-1} \mathrm{~s}^{-1}$ [41]). In the presence of TBA (up to $6 \mathrm{mM}$ ) no effect was observed on the PARA degradation [Fig. $\mathrm{S} 5$ ] indicating that hydroxyl radical are not generated using $\mathrm{Co}(\mathrm{II}) 0.1 \mathrm{mM}$ and $\mathrm{SO}_{3}{ }^{2-}$ $1 \mathrm{mM}$ at $\mathrm{pH}$ 9.0. Indeed, if hydroxyl radical were produced in the system, addition of 1 mM TBA should be scavenged about $98 \% \mathrm{HO}^{\bullet}$ reducing drastically the PARA degradation. However, when EtOH was used as radical scavenger in solution (Fig. 4) PARA degradation rate and efficiency (after $30 \mathrm{~min}$ ) were modified. In the presence of $500 \mathrm{mM}$ of EtOH, a complete inhibition of PARA degradation should be expected on the basis of second order rate constant reported before. But, PARA is still degraded with $\sim 29 \%$ of disappearance after $30 \mathrm{~min}$. Such trend could be explained considering the possible involvement of $\mathrm{SO}_{5}{ }^{\bullet-}$ during PARA degradation. In fact, $\mathrm{EtOH}$ is not able to scavenge strongly $\mathrm{SO}_{5}{ }^{--}$due to the very low rate constant $\left(k_{E t O H, S O_{5}^{--}}<10^{3} \mathrm{M}^{-1} \mathrm{~s}^{-1}\right.$ [46]).

Such results suggest that $\mathrm{SO}_{4}{ }^{--}$represent the main radical leading to the degradation, but also possible implication of $\mathrm{SO}_{5}{ }^{--}$during degradation of PARA is possible.

\subsection{Heterogeneous reaction between $\mathrm{CoO}$ and $\mathrm{SO}_{3}{ }^{2-}$}

Cobalt oxide such as $\mathrm{CoO}, \mathrm{CoO}_{2}, \mathrm{CoO}(\mathrm{OH}), \mathrm{Co}_{2} \mathrm{O}_{3}$ and $\mathrm{Co}_{3} \mathrm{O}_{4}$ were usually used to react with PMS to oxidize different kinds of organic pollutants [24]. Experiments to prove the efficiency of sulfite activation by $\mathrm{CoO}$ were conducted at $\mathrm{pH} 9.0$ with the 
paracetamol concentration of $10 \mu \mathrm{M}$ and $\mathrm{SO}_{3}{ }^{2-}$ at $1.0 \mathrm{mM}$. As shown in Fig. 5, when $0.1 \mathrm{mM}$ and $1.0 \mathrm{mM} \mathrm{CoO}$ were added to the solution, the degradation efficiency were $32.9 \%$ and $71.7 \%$, after 30 min respectively, which indicates that $\mathrm{CoO}$ exhibit a good catalytic activity. One of heterogeneous catalysts advantages belong to their stability and their reusability as catalyst. However, oxide can easily agglomerate during catalytic reaction, resulting in the reduction of catalytic performance [47], also cobalt ion leaching and dissolving problem can cause the same potential environmental and health problem as homogeneous catalysts do. As reported in Fig. 5 and Fig. 2A, the initial degradation rate is completely different in the two systems, very fast with soluble Co(II) and much slower with $\mathrm{CoO}$. This observation shows that the reactivity of sulfite with cobalt is efficient in homogeneous phase and so with cobalt oxide a first process of solubilisation seems necessary.

\subsection{Sequential experiments for high concentration paracetamol}

Sequential experiments were performed with multiple additions of S(IV) to enhance the degradation of high concentration of paracetamol in this $\mathrm{Co}$ (II)-S(IV) system. In the experiment, the concentration of paracetamol was $500 \mu \mathrm{M}, \mathrm{Co}$ (II) was $0.5 \mathrm{mM}$, and the initial $\mathrm{pH}$ value of solution was adjusted to 9.0 and then controlled during the whole reaction. $5 \mathrm{mM} \mathrm{S}$ (IV) was added to the solution at the beginning, while $0.5 \mathrm{mM}$ were spiked every $20 \mathrm{~min}$. After $200 \mathrm{~min}$ of reaction, (Fig. S6) nearly complete PARA degradation was archived. Compared to $\mathrm{Co}(\mathrm{II})$, which is recycled during the reaction, sulfite is consumed as transforms into $\mathrm{SO}_{3}{ }^{--}$and subsequently into $\mathrm{SO}_{4}{ }^{2-}$. So due to the depletion of $\mathrm{S}(\mathrm{IV})$, multiple additional sulfite is necessary to promote sequential treatment.

\section{Conclusion}

Our results showed the high efficiency of this Co(II)-S(IV) system using PARA as organic pollutant model in aqueous solution at alkaline $\mathrm{pH}$. In this system, the degradation of paracetamol depend on initial concentrations of S(IV) and strongly the $\mathrm{pH}$. In fact, it is clear that dissolved oxygen plays a crucial role allowing the oxysulfure 
295 radicals oxidation to initiate the reaction. The results of radical scavenger experiments 296 demonstrate that $\mathrm{SO}_{4}{ }^{--}$and also $\mathrm{SO}_{5}{ }^{--}$(to a lesser extent) are involved during the 297 paracetamol degradation. Furthermore, heterogeneous catalyst $\mathrm{CoO}$ also could react 298 with sulfite to degrade paracetamol to a large extent. In general, this research work 299 provides a new promising strategy by using sulfite and transition metal Co(II) to 300 degrade organic compounds in wastewater under alkaline environment. One of the 301 perspectives of this work is to perform same experiments with other metals in order to 302 assess their ability to promote the radical generation from sulfite under dark and light 303 conditions. 


\section{Acknowledgement}

This work was supported by the National Natural Science Foundation of China (NSFC-CNRS_PRC No. 21711530144 and CNRS No. 270437) .This work was also supported by the "Federation des Recherches en Environnement" through the CPER "Environnement" founded by the "Région Auvergne," the French government and FEDER from European community. The authors gratefully acknowledge financial support from China Scholarship Council provided to Yanan Yuan to study at the University Clermont Auvergne in Clermont-Ferrand, France.

\section{References}

[1] G.P. Anipsitakis, D.D. Dionysiou, Environ. Sci. Technol. 37 (2003) 4790-4797.

[2] P. Shukla, H. Sun, S. Wang, H.M. Ang, M.O. Tadé, Catal. Today 175 (2011) 380-385.

[3] Y. Zuo, J. Zhan, T. Wu, J. Atmos. Chem. 50 (2005) 195-210.

[4] P. Neta, R.E. Huie, A.B. Ross, J. Phys. Chem. Ref. Data 17 (1988) 1027-1284.

[5] H.V. Lutze, S. Bircher, I. Rapp, N. Kerlin, R. Bakkour, M. Geisler, C. von Sonntag, T.C. Schmidt, Environ. Sci. Technol. 49 (2015) 1673-1680.

[6] Y. Ren, L. Lin, J. Ma, J. Yang, J. Feng, Z. Fan, Appl. Catal., B 165 (2015) 572-578.

[7] G.P. Anipsitakis, D.D. Dionysiou, M.A. Gonzalez, Environ. Sci. Technol. 40 (2006) 1000-1007.

[8] Y.-T. Lin, C. Liang, J.-H. Chen, Chemosphere 82 (2011) 1168-1172.

[9] X. Xie, Y. Zhang, W. Huang, S. Huang, J. Environ. Sci. 24 (2012) 821-826.

[10] M.G. Antoniou, A.A. de la Cruz, D.D. Dionysiou, Appl. Catal., B 96 (2010) 290-298.

[11] J. Criquet, N. Karpel Vel Leitner, Chem. Eng. J. 169 (2011) 258-262.

[12] H. Guo, N. Gao, Y. Yang, Y. Zhang, Chem. Eng. J. 292 (2016) 82-91.

[13] L.W. Matzek, K.E. Carter, Chemosphere 151 (2016) 178-188.

[14] Y. Wu, R. Prulho, M. Brigante, W. Dong, K. Hanna, G. Mailhot, J. Hazard. Mater. 322, Part B (2017) 380-386.

[15] Y. Wu, A. Bianco, M. Brigante, W. Dong, P. de Sainte-Claire, K. Hanna, G. Mailhot, Environ. Sci. Technol. 49 (2015) 14343-14349.

[16] C. Qi, X. Liu, J. Ma, C. Lin, X. Li, H. Zhang, Chemosphere 151 (2016) 280-288.

[17] T. Zhang, H. Zhu, J.-P. Croué, Environ. Sci. Technol. 47 (2013) 2784-2791.

[18] A.B. Kurukutla, P.S.S. Kumar, S. Anandan, T. Sivasankar, Environ. Eng. Sci. 32 (2014) 129-140.

[19] Y.-F. Huang, Y.-H. Huang, J. Hazard. Mater. 167 (2009) 418-426.

[20] A. Rastogi, S.R. Al-Abed, D.D. Dionysiou, Appl. Catal., B 85 (2009) 171-179.

[21] F. Ghanbari, M. Moradi, Chem. Eng. J. 310, Part 1 (2017) 41-62.

[22] H. Liang, H. Sun, A. Patel, P. Shukla, Z.H. Zhu, S. Wang, Appl. Catal., B 127 (2012) 330-335.

[23] M. Stoyanova, I. Slavova, S. Christoskova, V. Ivanova, Appl. Catal. A 476 (2014) 121-132.

[24] Y. Wang, L. Zhou, X. Duan, H. Sun, E.L. Tin, W. Jin, S. Wang, Catal. Today 258 (2015) 576-584.

[25] Y. Zhu, S. Chen, X. Quan, Y. Zhang, RSC Adv. 3 (2013) 520-525.

[26] L. Chen, X. Peng, J. Liu, J. Li, F. Wu, Ind. Eng. Chem. Res. 51 (2012) 13632-13638. 
346 [27] Z. Liu, S. Yang, Y. Yuan, J. Xu, Y. Zhu, J. Li, F. Wu, J. Hazard. Mater. 324, Part B (2017) 583-592.

347 [28] Y. Yuan, S. Yang, D. Zhou, F. Wu, J. Hazard. Mater. 307 (2016) 294-301.

348 [29] D. Zhou, L. Chen, C. Zhang, Y. Yu, L. Zhang, F. Wu, Water Res. 57 (2014) 87-95.

349 [30] D. Zhou, Y. Yuan, S. Yang, H. Gao, L. Chen, J. Sulfur Chem. 36 (2015) 373-384.

350 [31] D.T.F. Kuo, D.W. Kirk, C.Q. Jia, J. Sulfur Chem. 27 (2006) 461-530.

351 [32] Y. Zuo, Geochim. Cosmochim. Acta 59 (1995) 3123-3130.

352 [33] Y. Zuo, J. Zhan, Atmos. Environ. 39 (2005) 27-37.

353 [34] M.J. Benotti, R.A. Trenholm, B.J. Vanderford, J.C. Holady, B.D. Stanford, S.A. Snyder, Environ. 354 Sci. Technol. 43 (2009) 597-603.

355 [35] L. Zhang, J. Hu, R. Zhu, Q. Zhou, J. Chen, Appl. Microbiol. Biotechnol. 97 (2013) 3687-3698.

356 [36] D. Katakis, A.O. Allen, J. Phys. Chem. 68 (1964) 1359-1362.

357 [37] K.H. Chan, W. Chu, Water Res. 43 (2009) 2513-2521.

358 [38] W. Pasiuk-Bronikowska, T. Bronikowski, M. Ulejczyk, Environ. Sci. Technol. 26 (1992) 359 1976-1981.

360 [39] R.E. Huie, P. Neta, J. Phys. Chem. 88 (1984) 5665-5669.

361 [40] G.V. Buxton, S. McGowan, G.A. Salmon, J.E. Williams, N.D. Wood, Atmos. Environ. 30 (1996) 362 2483-2493.

363 [41] U. Deister, P. Warneck, J. Phys. Chem. 94 (1990) 2191-2198.

364 [42] R.E. Huie, P. Neta, Atmos. Environ. 21 (1987) 1743-1747.

365 [43] P.H. Wine, Y. Tang, R.P. Thorn, J.R. Wells, D.D. Davis, J. Geophys. Res. 94 (1989) 1085-1094.

366 [44] G.V. Buxton, C.L. Greenstock, W.P. Helman, A.B. Ross, J. Phys. Chem. Ref. Data 17 (1988)

367 513-886.

368 [45] C.L. Clifton, R.E. Huie, Int. J. Chem. Kinet. 21 (1989) 677-687.

369 [46] E. Hayon, A. Treinin, J. Wilf, J. Am. Chem. Soc. 94 (1972) 47-57.

370 [47] J. Deng, S. Feng, K. Zhang, J. Li, H. Wang, T. Zhang, X. Ma, Chem. Eng. J. 308 (2017) 505-515. 
Fig. 1: Effect of initial $\mathrm{pH}$ values on PARA degradation. Condition: $[\mathrm{PARA}]_{0}=10 \mu \mathrm{M}$, $[\mathrm{Co}(\mathrm{II})]_{0}=0.1 \mathrm{mM},\left[\mathrm{Na}_{2} \mathrm{SO}_{3}\right]_{0}=1.0 \mathrm{mM}, \mathrm{T}=25^{\circ} \mathrm{C}, \mathrm{F}_{\mathrm{air}}=0.8 \mathrm{~L} \mathrm{~min}^{-1}$.

376

Fig. 2: Effect of (A) Co(II) and (B) S(IV) concentrations on PARA degradation. Condition: $[\mathrm{PARA}]_{0}=10 \mu \mathrm{M}, \mathrm{pH}_{0}=9.0, \mathrm{~T}=25^{\circ} \mathrm{C}, \mathrm{F}_{\mathrm{air}}=0.8 \mathrm{~L} \mathrm{~min}^{-1}$.

379

380

Fig. 3: Effect of oxygen on PARA degradation. Condition: $[\mathrm{PARA}]_{0}=10 \mu \mathrm{M},[\mathrm{Co}(\mathrm{II})]_{0}$ 381 $=0.1 \mathrm{mM},\left[\mathrm{Na}_{2} \mathrm{SO}_{3}\right]_{0}=1.0 \mathrm{mM}, \mathrm{pH}_{0}=9.0, \mathrm{~T}=25^{\circ} \mathrm{C}, \mathrm{F}_{\text {air }}=0.8 \mathrm{~L} \mathrm{~min}^{-1}$.

382

383

384

385

386

Fig.4: Effect of radical scavenger of EtOH on PARA degradation.

Condition: $[\mathrm{PARA}]_{0}=10 \mu \mathrm{M},[\mathrm{Co}(\mathrm{II})]_{0}=0.1 \mathrm{mM},\left[\mathrm{Na}_{2} \mathrm{SO}_{3}\right]_{0}=1.0 \mathrm{mM}, \mathrm{pH}_{0}=9.0, \mathrm{~T}=$ $25^{\circ} \mathrm{C}, \mathrm{F}_{\mathrm{air}}=0.8 \mathrm{~L} \mathrm{~min}^{-1}$.

387

Fig. 5: Effect of heterogeneous catalyst $\mathrm{CoO}$ react with $\mathrm{S}(\mathrm{IV})$ to degrade PARA.

390

Condition: $[\mathrm{PARA}]_{0}=10 \mu \mathrm{M},\left[\mathrm{Na}_{2} \mathrm{SO}_{3}\right]_{0}=1.0 \mathrm{mM}, \mathrm{pH}_{0}=9.0, \mathrm{~T}=25^{\circ} \mathrm{C}, \mathrm{F}_{\text {air }}=0.8 \mathrm{~L}$ $\min ^{-1}$.

391 

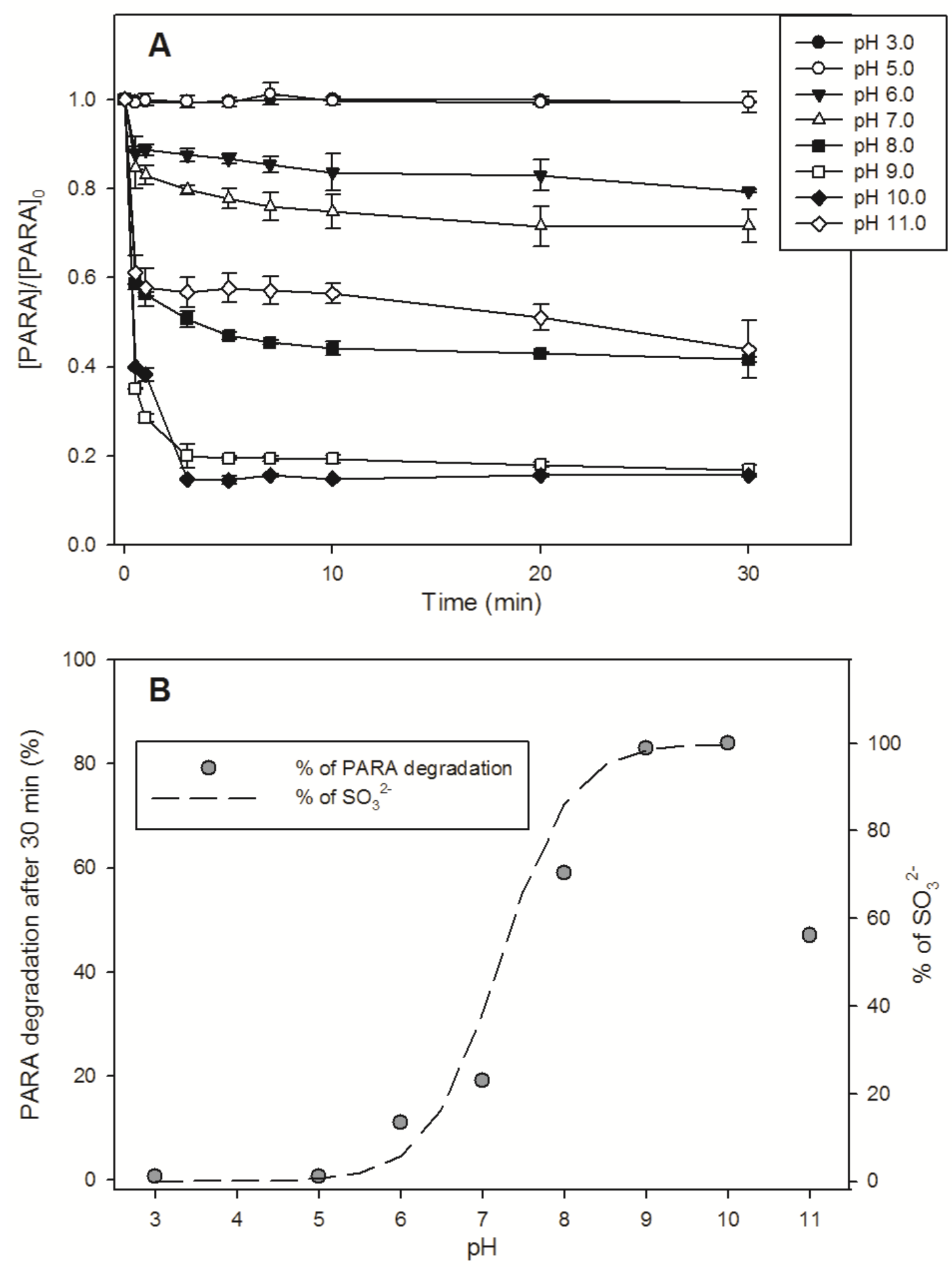

Fig. 1

394 

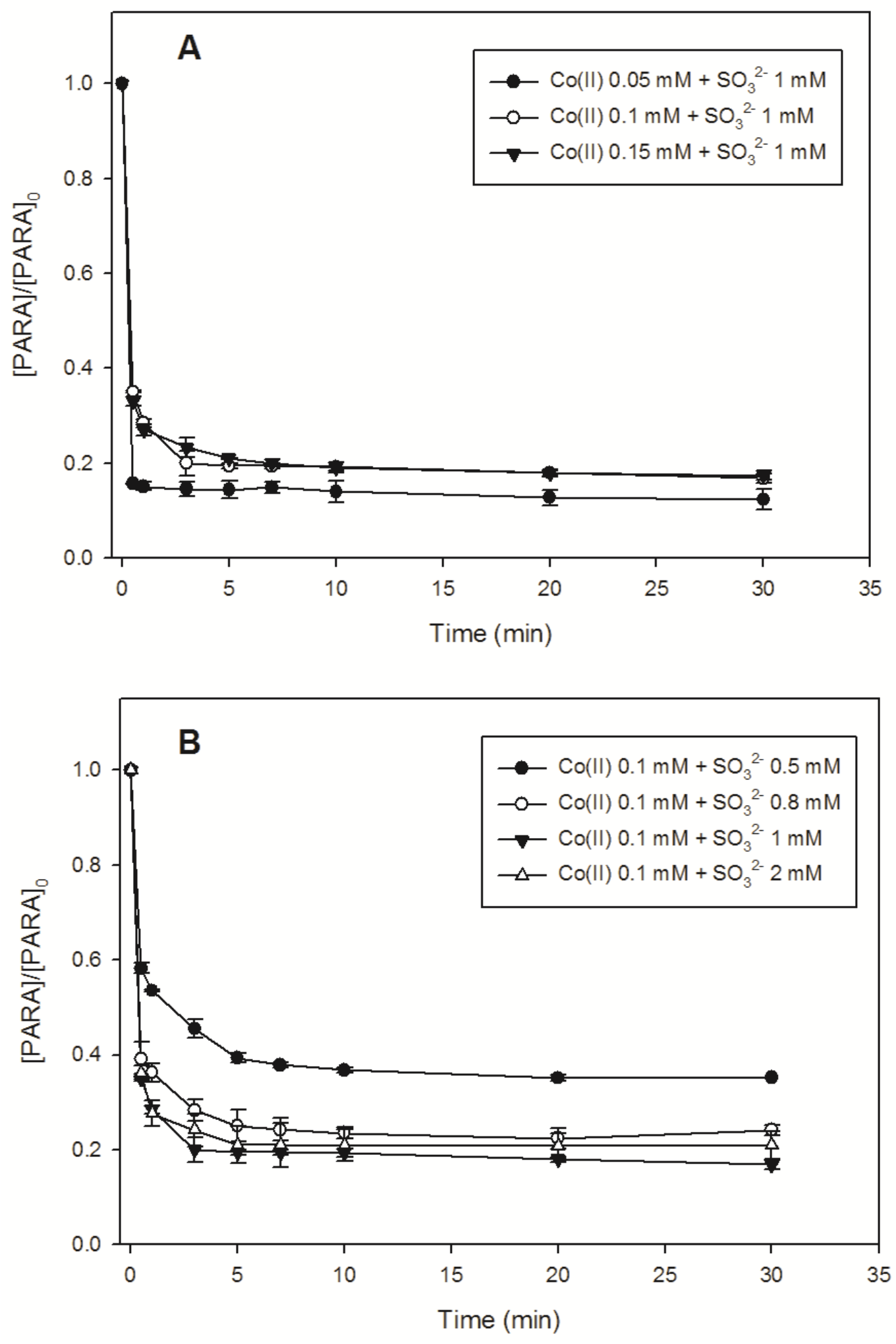

Fig. 2 


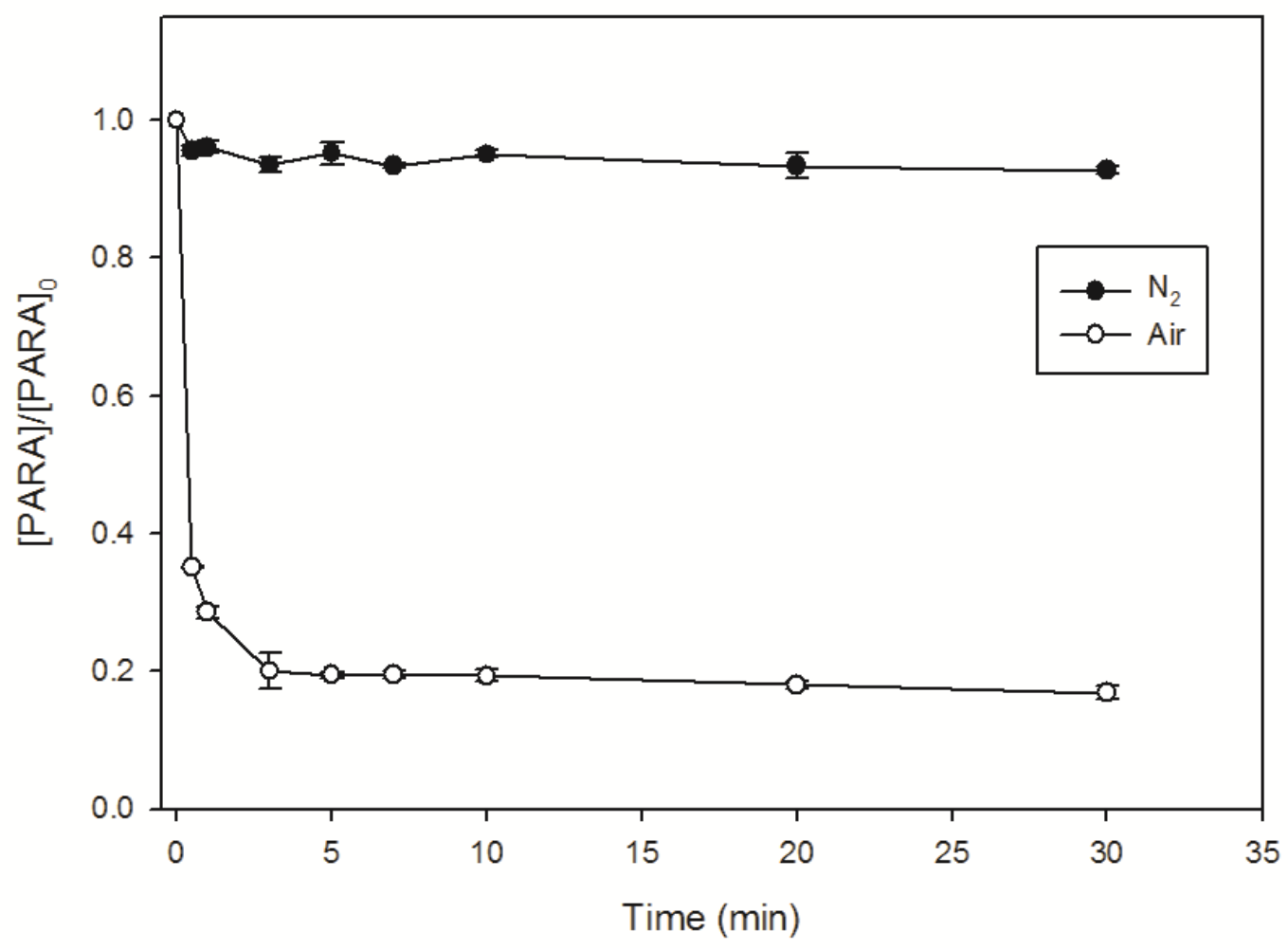

399

Fig. 3.

401 


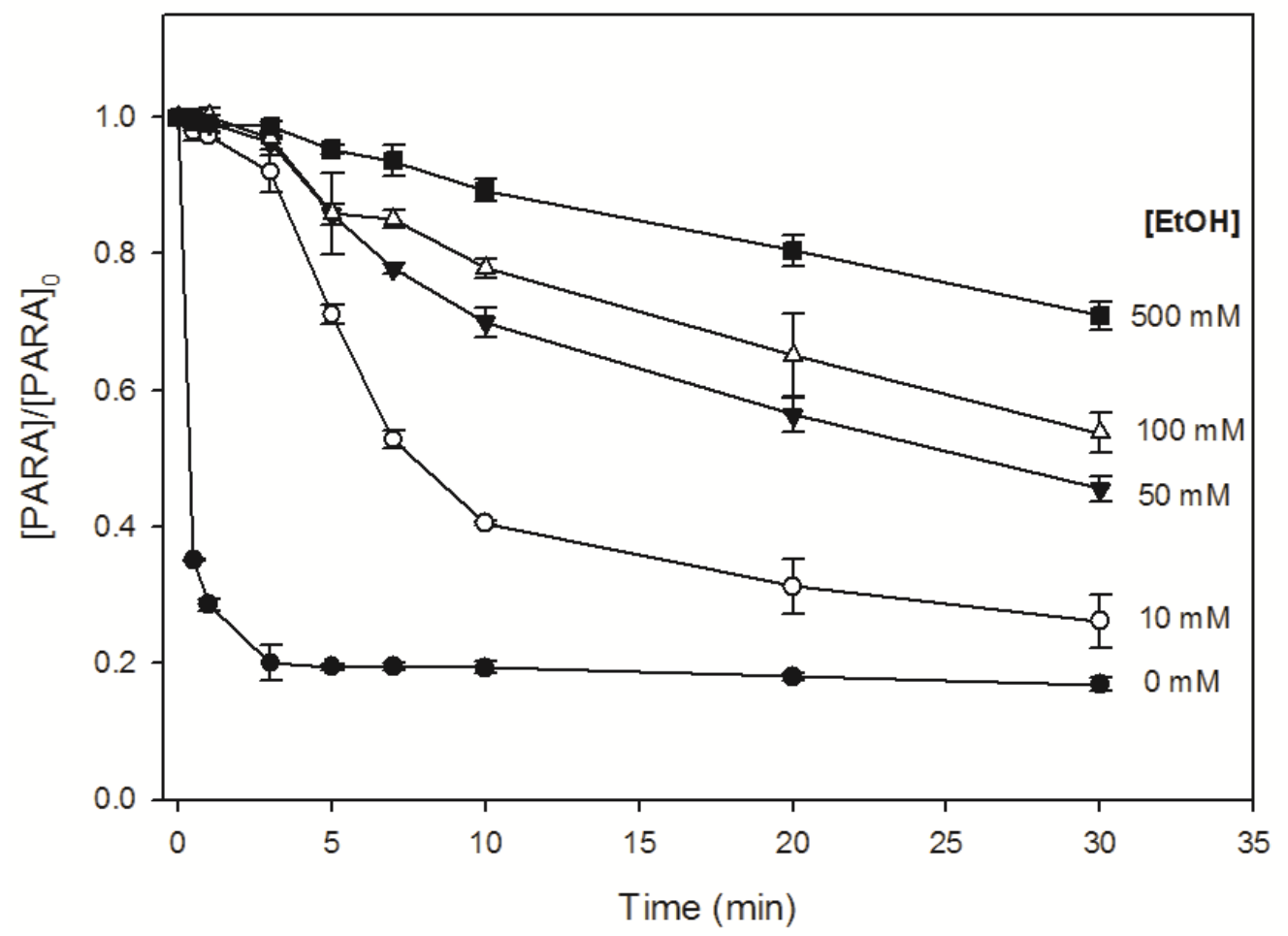

402

Fig.4.

404 


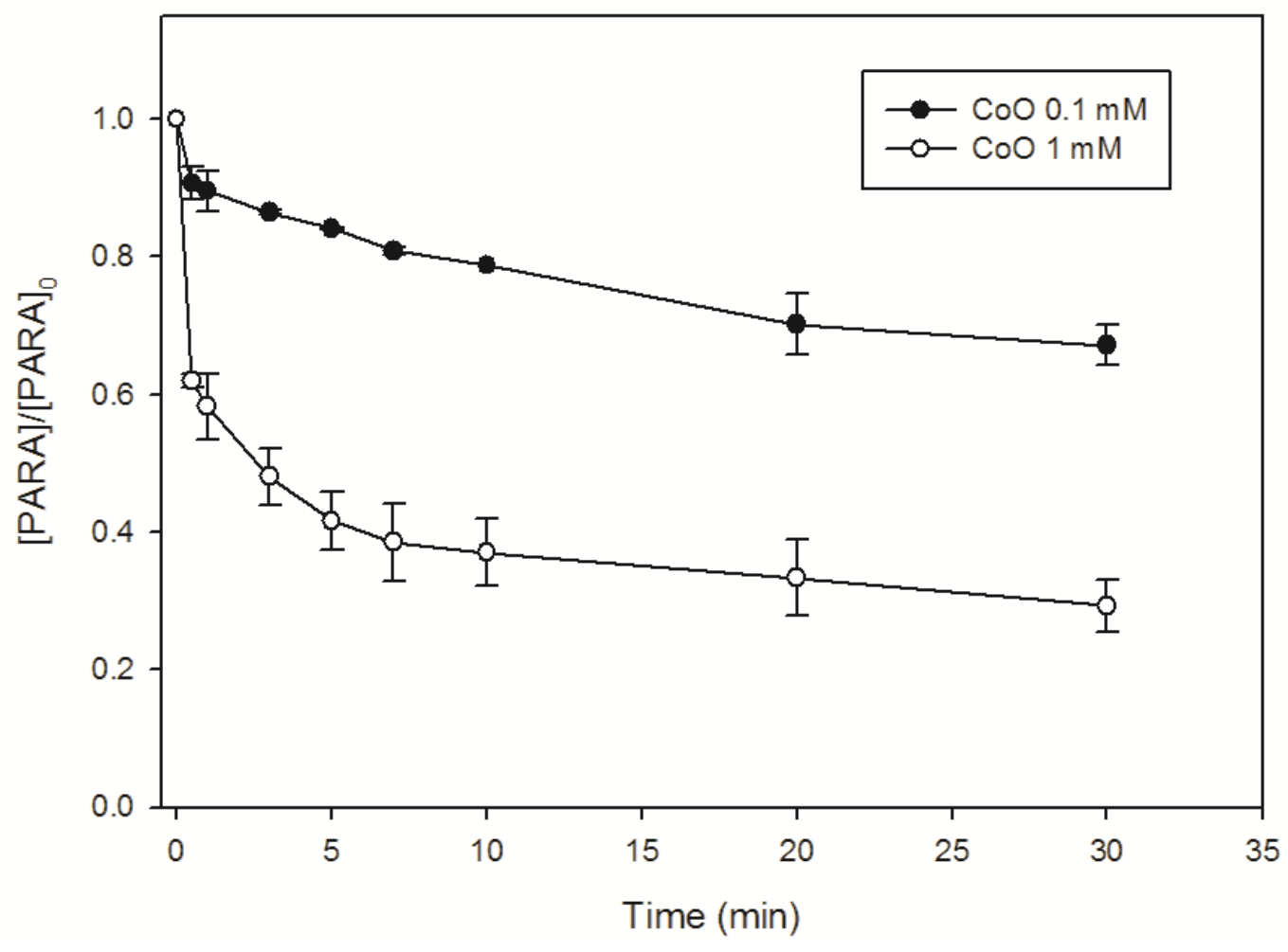

405

Fig. 5

407

408 
Supplementary material

410

411

412

\title{
Rapid Oxidation of Organic Contaminants by Cobalt(II) Catalyzed
}

\section{Sulfite at Alkaline pH}

\author{
Yanan Yuan ${ }^{1,2}$, Dan Zhao ${ }^{1}$, Jinjun $\mathrm{Li}^{1}$, Feng Wu ${ }^{1 *}$, Marcello Brigante ${ }^{2}$, Gilles
}

Mailhot $^{2^{*}}$

${ }^{1}$ Department of Environmental Science, School of Resources and Environmental Science, Wuhan University, Wuhan, 430079, China.

${ }^{2}$ Université Clermont Auvergne, CNRS, SIGMA Clermont, Institut de Chimie de Clermont-Ferrand, F-63000 Clermont-Ferrand, France.

Corresponding Authors: Feng Wu (fengwu@whu.edu.cn) and Gilles Mailhot

(gilles.mailhot@uca.fr)

\section{Preliminary experiment using Co(II)-S(IV)}

A typical degradation of Paracetamol by three different kinds of system (only Co(II), only sulfite(S(IV), Co(II)+S(IV)) is presented in Fig.S0. The result showed that when the experiment conducted in the presence of S(IV) without any catalyst, negligible change in paracetamol concentration was observed. A similar trend was also achieved in the experiment by only using Co(II) even after being centrifuged for $15 \mathrm{~min}$ at 9000 rpm. There was no precipitation occurred, which illustrated that there is no adsorption in this system and neither S(IV) nor Co(II) added to the reagent had an effect on Paracetamol. However, when both S(IV) and Co(II) were in solution, Paracetamol can be degraded to more than $80 \%$ in 10 min. These results suggest that Paracetamol degradation depends heavily on the reaction between $\mathrm{S}(\mathrm{IV})$ and $\mathrm{Co}(\mathrm{II})$, it proceeded only when S(IV) and Co(II) were present. 


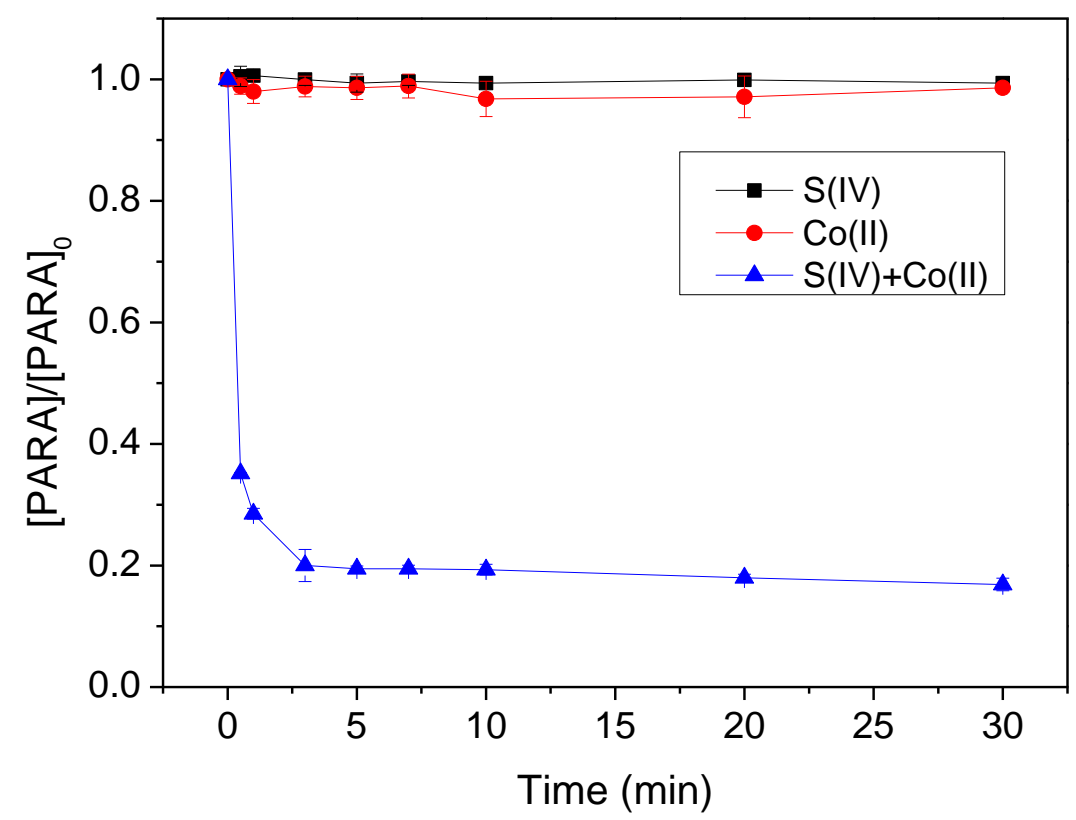

436

437 Fig.S0 The effect of control experiments under various conditions on paracetamol 438 degradation. Condition: $[\mathrm{PARA}]_{0}=10 \mu \mathrm{M},[\mathrm{Co}(\mathrm{II})]_{0}=0.1 \mathrm{mM},\left[\mathrm{Na}_{2} \mathrm{SO}_{3}\right]_{0}=1.0$ 439 $\mathrm{mM}, \mathrm{pH}_{0}=9.0, \mathrm{~T}=25^{\circ} \mathrm{C}, \mathrm{F}_{\mathrm{air}}=0.8 \mathrm{~L} \mathrm{~min}^{-1}$.

440

441 


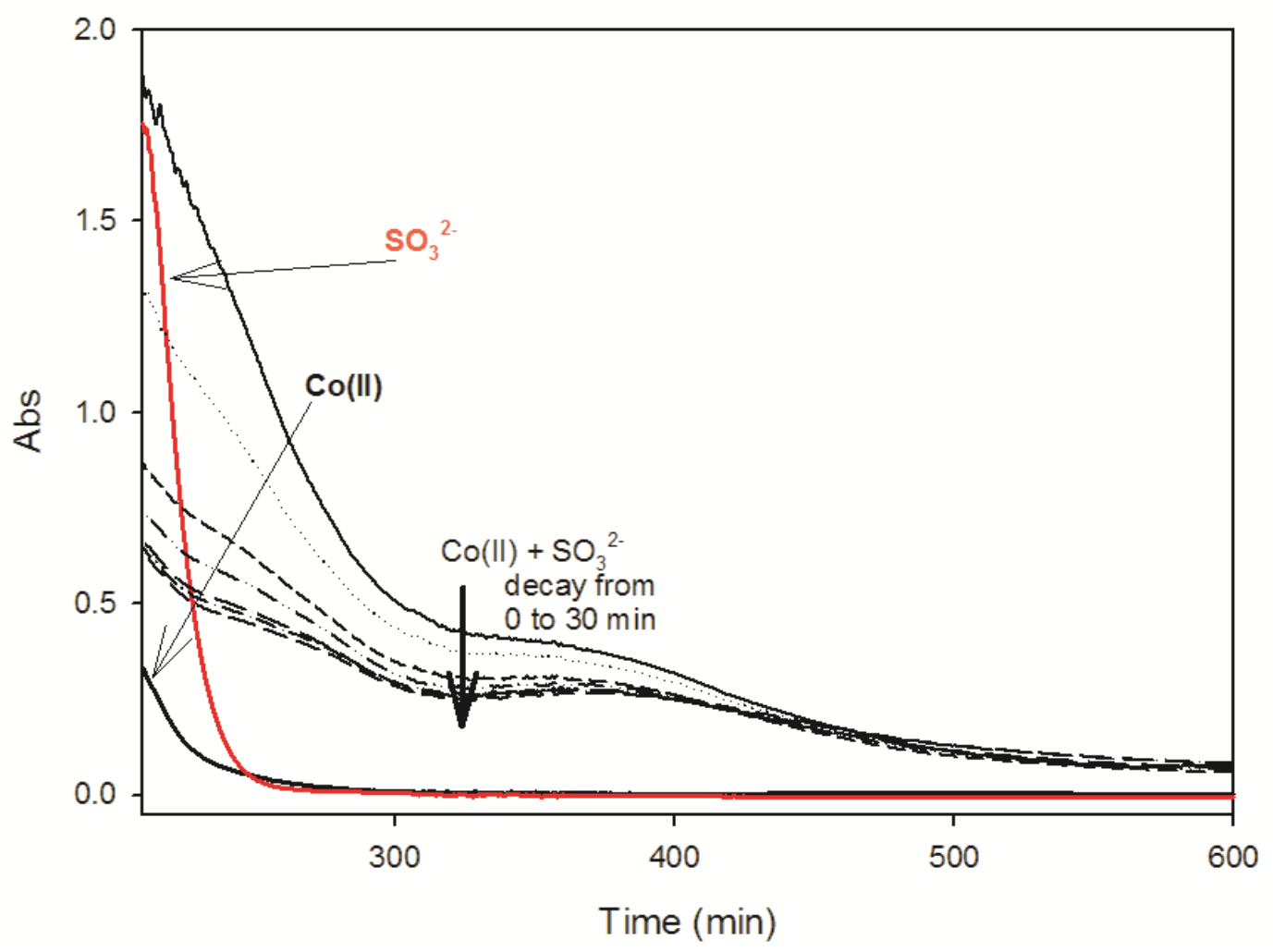

Fig. S1. UV-vis spectra of reaction solution at specific time intervals during the reaction. Conditions: $[\mathrm{Co}(\mathrm{II})]_{0}=0.1 \mathrm{mM},\left[\mathrm{Na}_{2} \mathrm{SO}_{3}\right]_{0}=1.0 \mathrm{mM}, \mathrm{pH}_{0}=9.0, \mathrm{~T}$ $=25^{\circ} \mathrm{C}, \mathrm{F}_{\mathrm{air}}=0.8 \mathrm{~L} \mathrm{~min}^{-1}$.

\section{Cobalt(II) quantification}

453 The calibration of Cobalt(II) was measured by preparing a series of standard solutions, 454 firstly, $5 \mathrm{~mL}$ cobalt(II) and $1 \mathrm{~mL} \mathrm{NH}_{4} \mathrm{SCN}(566 \mathrm{~g} / \mathrm{L})$ was added to a $10 \mathrm{~mL}$ centrifuge tube and hand shaken for $1 \mathrm{~min}$, then another $4 \mathrm{~mL}$ pure MIK was added to the mixture, and ultrasonic shaking for $1 \mathrm{~min}$ and equilibrating until stratication occurred. Using the UV-Vis spectrophotometer for the absorbance at $620 \mathrm{~nm}$ for the upper layer complex which containing Cobalt(II). The calibration curve is presented in Fig. S2a. 
459

460

461

$\left[\mathrm{Co}^{2+}\right](\mathrm{M})=\left(6.77 \times 10^{-4} \times \mathrm{Abs}_{620 \mathrm{~nm}}\right)-7.02 \times 10^{-6}$

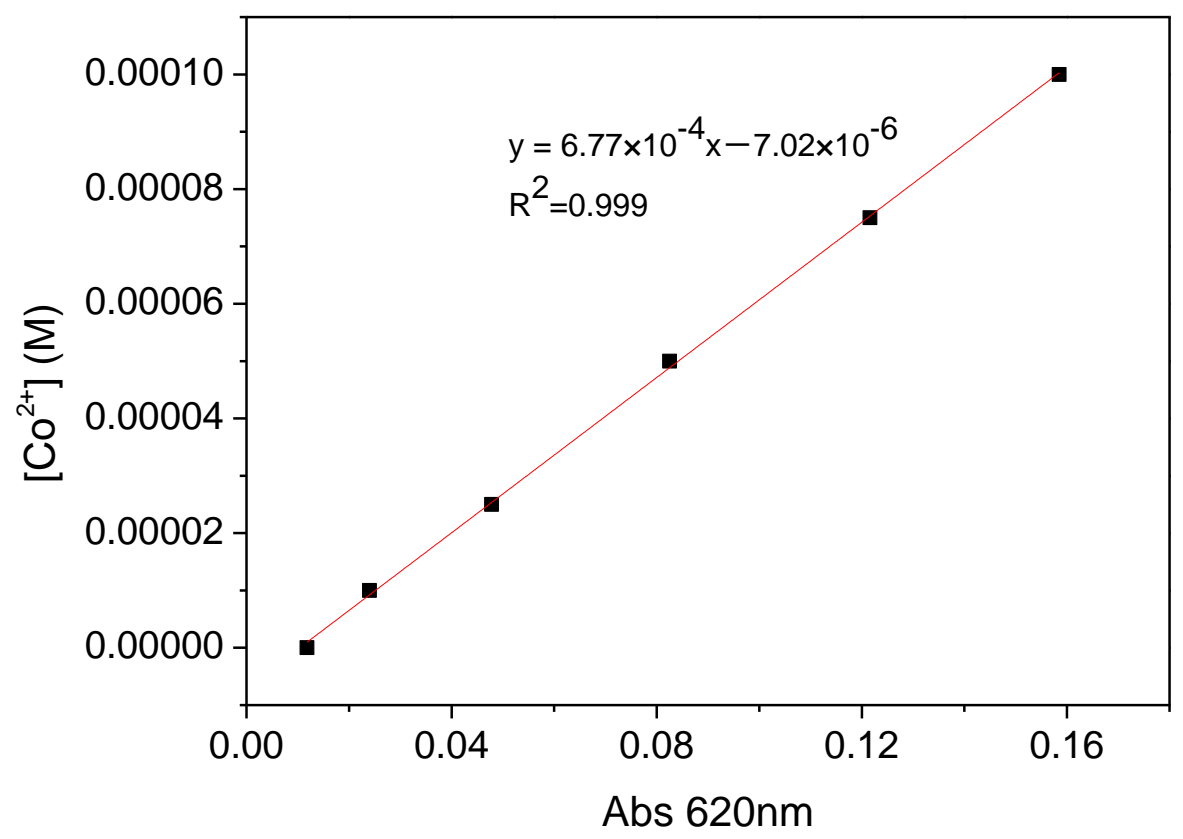

462

463

464

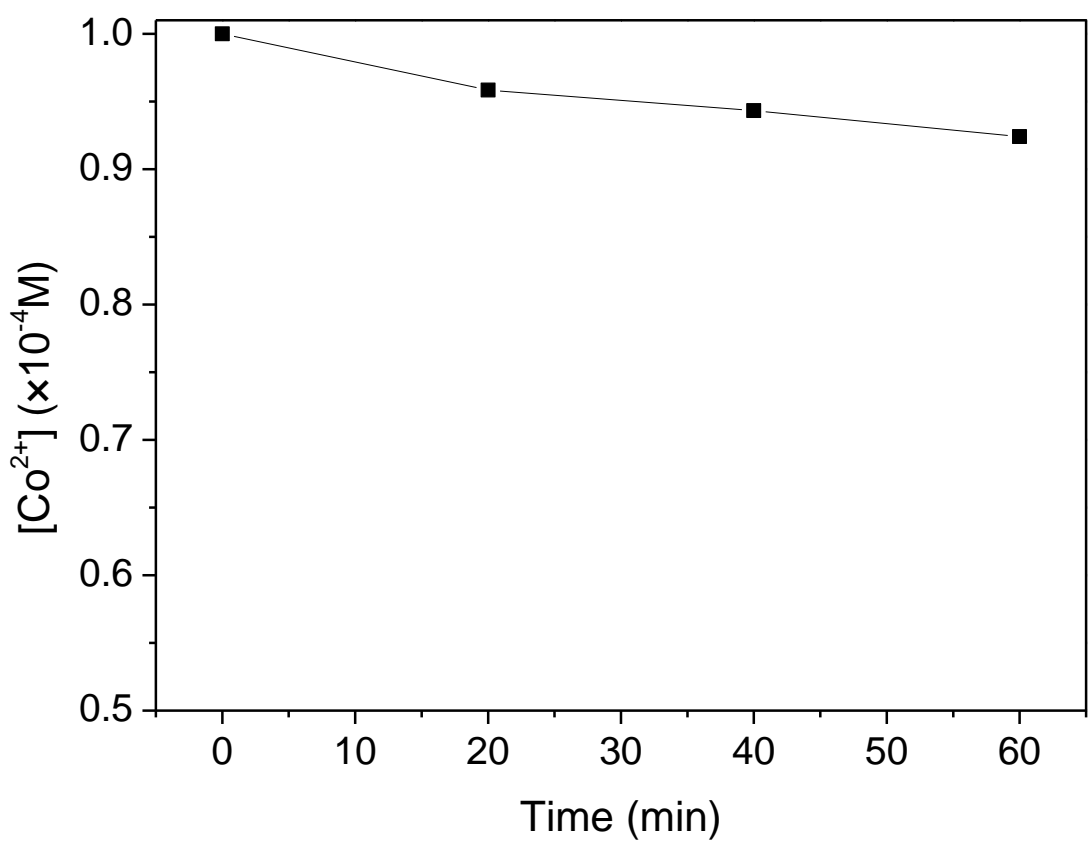

Fig.S2. Co(II) concentration vs Abs at $620 \mathrm{~nm}$ using described method 
9.0, $\mathrm{T}=25^{\circ} \mathrm{C}, \mathrm{F}_{\mathrm{air}}=0.8 \mathrm{~L} \mathrm{~min}^{-1}$. 

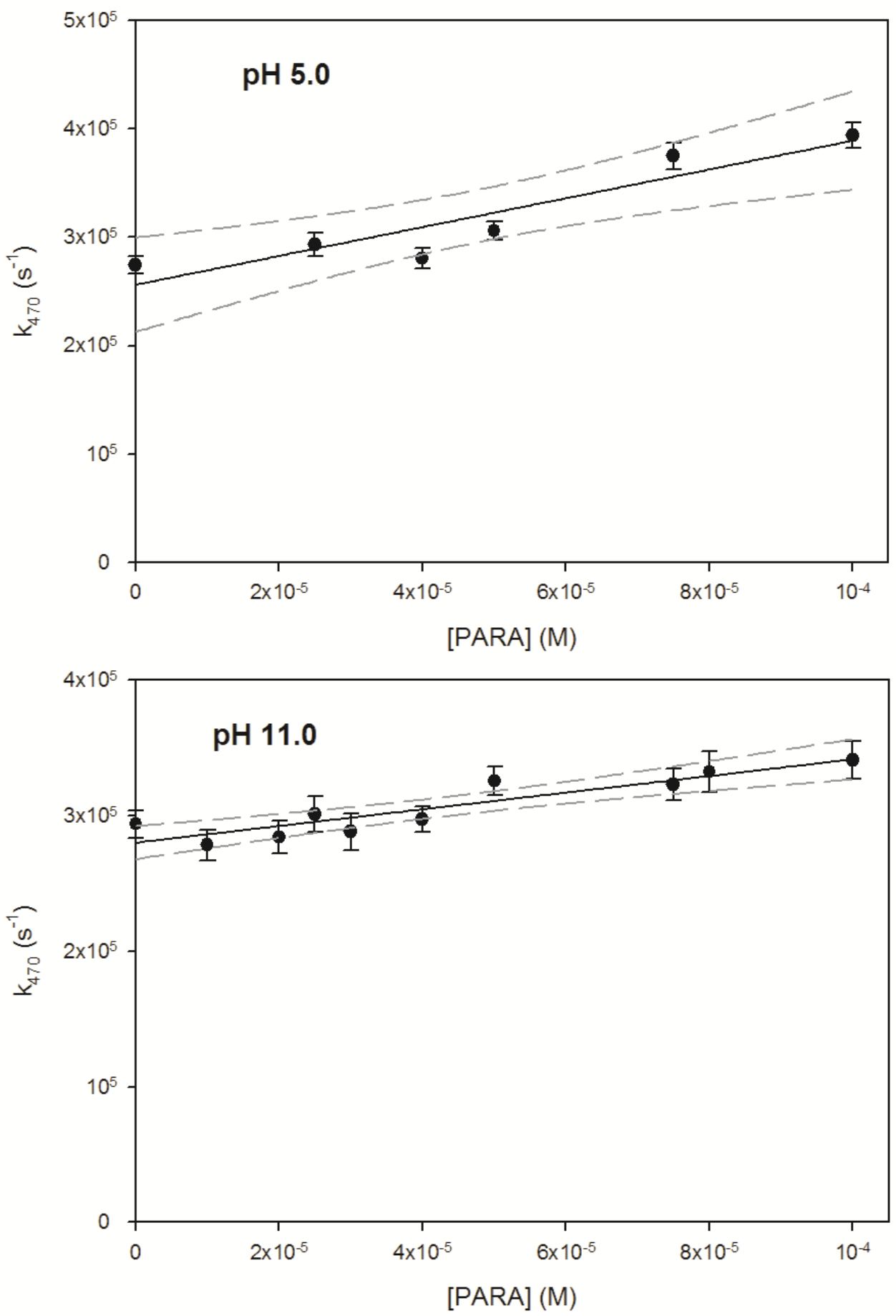

Fig. S4 : Pseudo-first order decay of sulfate radical monitored at $470 \mathrm{~nm}$ vs PARA concentration for molecular ( $\mathrm{pH}$ 5.0) and deprotonated form ( $\mathrm{pH}$ 11.0).solid line represents the linear fit of the experimental data and the dashed lines denote the $95 \%$ confidence interval of this fit. 


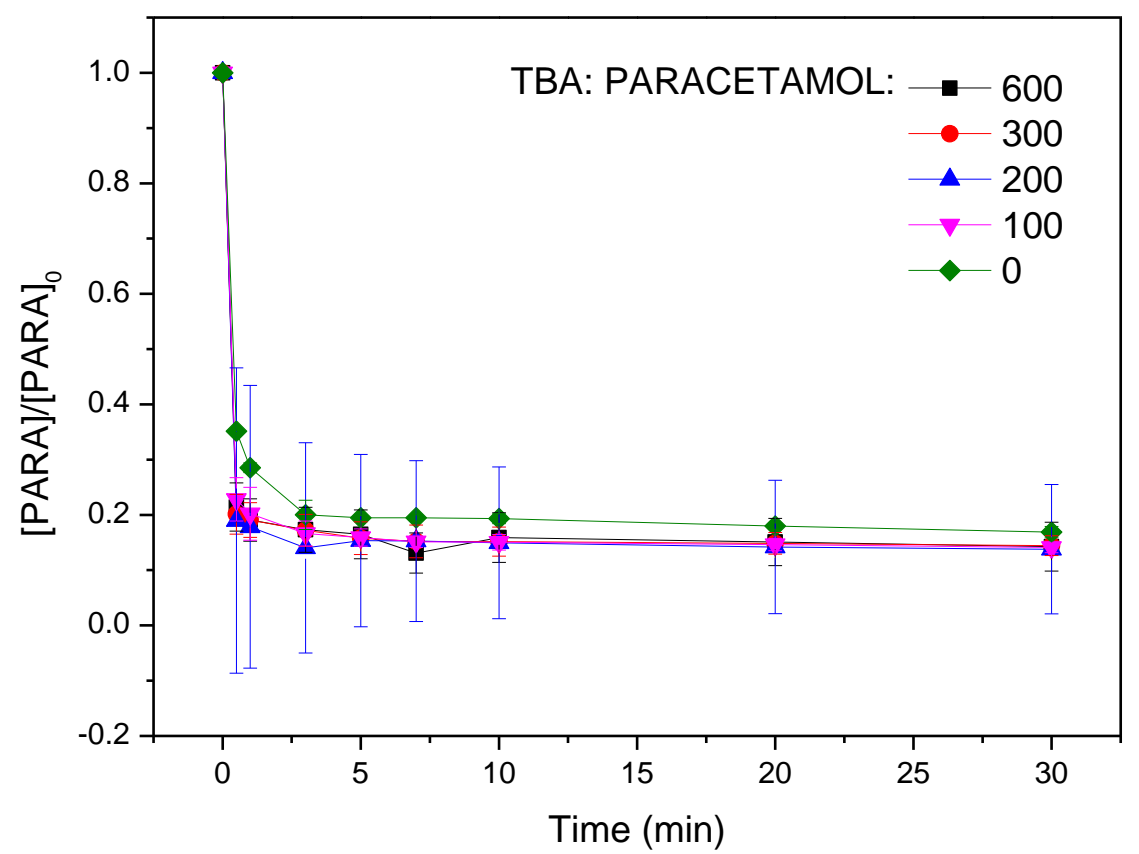

478

479 Fig. S5. Effect of TBA on paracetamol degradation.

480 Condition: $[\mathrm{PARA}]_{0}=10 \mu \mathrm{M},[\mathrm{Co}(\mathrm{II})]_{0}=0.1 \mathrm{mM},\left[\mathrm{Na}_{2} \mathrm{SO}_{3}\right]_{0}=1.0 \mathrm{mM}, \mathrm{pH}_{0}=$ 481 9.0, $\mathrm{T}=25^{\circ} \mathrm{C}, \mathrm{F}_{\mathrm{air}}=0.8 \mathrm{~L} \mathrm{~min}^{-1}$.

482 


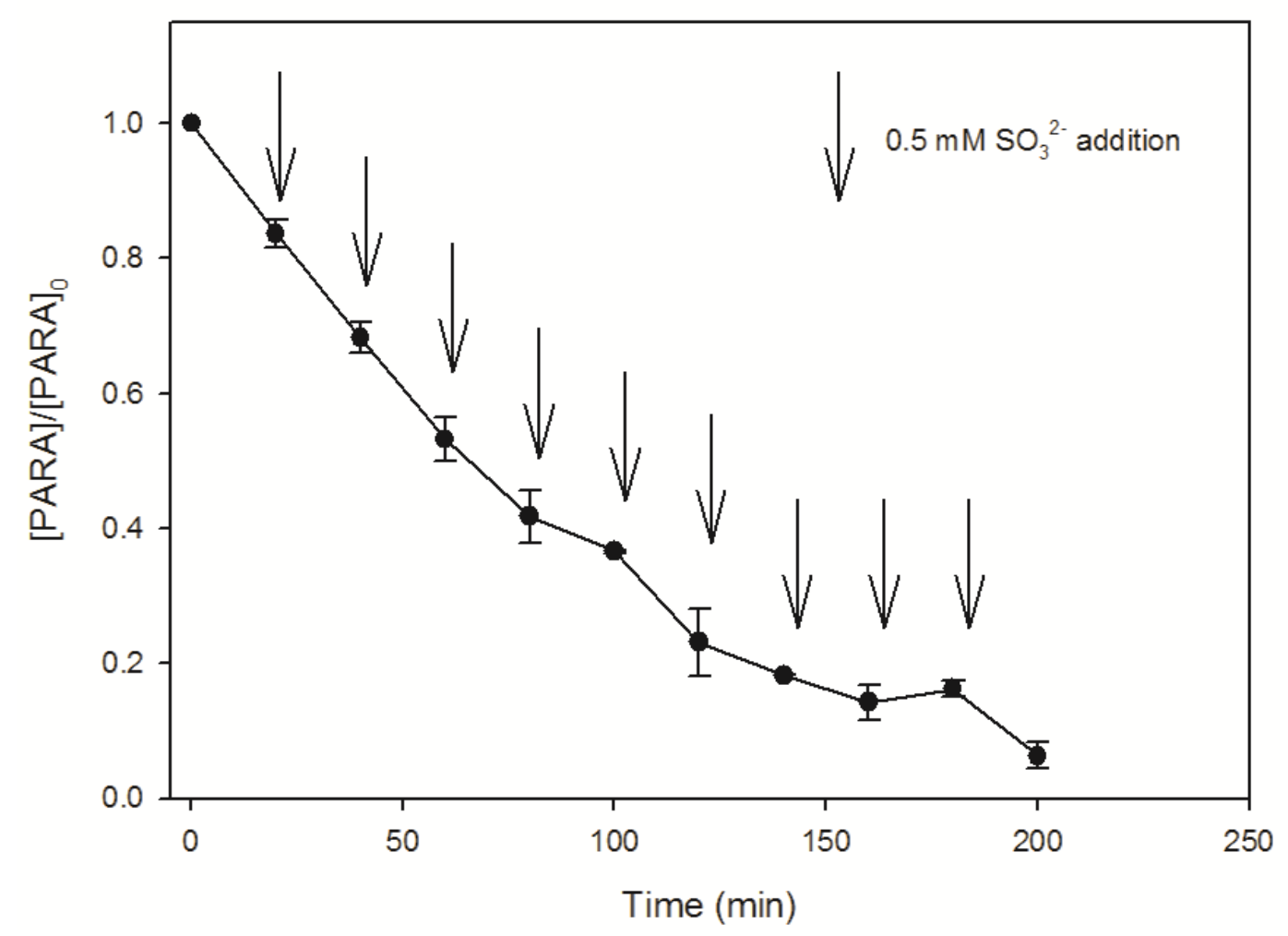

484

Fig. S6. Changes in paracetamol concentration over time in sequential experiments for 485 the oxidation of paracetamol at high concentration. Initial conditions: $[\mathrm{PARA}]_{0}=500$ 486 $\mu \mathrm{M},[\mathrm{Co}(\mathrm{II})]_{0}=0.5 \mathrm{mM},\left[\mathrm{Na}_{2} \mathrm{SO}_{3}\right]_{0}=5.0 \mathrm{mM}, \mathrm{pH}_{0}=9.0, \mathrm{~T}=25^{\circ} \mathrm{C}, \mathrm{F}_{\mathrm{air}}=0.8 \mathrm{~L} \mathrm{~min}^{-1}$. 487 Multiple additions of $0.5 \mathrm{mM} \mathrm{S(IV)} \mathrm{every} 20 \mathrm{~min}$. 